\title{
Validar a Guerra: A Construção do Regime de Expertise Estratégica*
}

Christophe Wasinski**

A guerra está infelizmente longe de desaparecer do cenário internacional. Após o término da Guerra Fria, ao longo da década de 1990 e no início dos anos 2000, forças armadas nacionais continuaram a se preparar para tal fenômeno, como demonstram os projetos de Revolução nos Assuntos Militares ou de Transformation nos Estados Unidos. Ademais, diversos exércitos envolveram-se regularmente em operações de guerra, como no Iraque em 1991, no Kosovo em

\footnotetext{
* Artigo recebido em 20 de outubro de 2012 e aprovado para publicação em 21 de dezembro de 2012. Traduzido por Paulo Chamon. E-mail: paulochamon@gmail.com. O autor agradece a Nina Wilsen pelos comentários pertinentes sobre uma versão anterior deste texto, e aos dois pareceristas anônimos da revista.

** Doutor em Ciência Política e professor do Centro de Pesquisa e Educação em Política Internacional (REPI) na Universidade de Namur e na Universidade Livre de Bruxelas. E-mail: christophe.wazinski@ulb.ac.be.
}

CONTEXTO INTERNACIONAL Rio de Janeiro, vol. 34, nº 2, julho/dezembro 2012, p. 435-470. 
1999, no Afeganistão desde 2001 e novamente no Iraque a partir de 2003. Todavia, como apontam Keith Krause e Michael C. Williams (1997, p. 51), surpreende que, a despeito de sua persistência, a violência guerreira permaneça pouco teorizada na área de Relações Internacionais.

O presente artigo ambiciona oferecer uma contribuição nessa temática. Nesse sentido, interroga os mecanismos do pensamento estratégico que contribuíram para tornar a guerra moderna uma prática social julgada tecnicamente viável e, assim, legítima para os militares. ${ }^{1}$ Para tal, a análise proposta inscreve-se nos campos da sociologia pragmática (inspirando-se em autores como Luc Boltanski, Nicolas Dodier e Francis Chateauraynaud) e da sociologia da ciência (apoiando-se fundamentalmente nos trabalhos de Bruno Latour). Por um lado, a sociologia da ciência desenvolveu uma problemática muito fértil acerca da construção dos fatos científicos que servirá de inspiração para este estudo. Por outro lado, a sociologia pragmática elaborou um quadro analítico das ações coletivas que se articula à pesquisa sobre a construção social dos fatos. A partir dessas abordagens, propõe-se a investigar a formação de um regime de expertise estratégica que sustenta a legitimidade técnica do uso da força militar. Juntas, a sociologia da ciência e a sociologia pragmática lançam luz sobre elementos particularmente importantes acerca da questão da guerra.

\section{Decisão Beligerante e Registros de Justificação}

As tentativas de explicação do fenômeno da guerra não são escassas, muito pelo contrário (SUGANAMI, 1990). Não obstante, muitas das abordagens tradicionais (como aquelas que insistem sobre a pesquisa do território, de matérias-primas ou ainda sobre a vontade de poder) tendem a silenciar amplamente um detalhe: o processo intersubjetivo por meio do qual os atores produzem representações comuns relativas à sua situação, seus problemas ou, ainda, às soluções tidas como 
Validar a Guerra: A Construção do Regime de Expertise Estratégica

possíveis para lidar com eles, o que nos acaba levando ao campo da guerra. ${ }^{2}$ Efetivamente, a guerra, enquanto ação social concertada e organizada, somente é possível caso exista, em sua origem, um consenso, mesmo que mínimo, frágil ou fragmentário, acerca da decisão de sua realização. Para capturar a ação política que é a guerra, portanto, convém interrogar-se sobre os grandes registros argumentativos (jurídico, moral, diplomático, metafórico etc.) que a justificam e permitem chegar a tal consenso. ${ }^{3}$

Com efeito, ao analisar-se com atenção um conflito internacional específico, identifica-se que diversas explicações acerca das razões para entrar em guerra se fazem presentes na fala de diplomatas, oficiais das Forças Armadas, políticos e outros especialistas. Pode-se afirmar que a decisão beligerante final recairá sobre a agregação, articulação e/ou hierarquização de diversos desses registros. Por exemplo, no caso da guerra de 2003 contra o Iraque, a existência de ditas "armas de destruição em massa" serviu de ponto focal ao redor do qual se organizaram justificativas colocando em questão a pessoa de Saddam Hussein, a obrigação moral de agir ou ainda laços entre o regime iraquiano e a Al Qaeda (WHITE HOUSE, 2002). Em suma, os tomadores de decisão negociam, entre si, um consenso que é expresso por meio de justificativas. ${ }^{4}$

No presente artigo, optou-se por analisar a construção de um único desses registros justificativos; aquele que afirma consistentemente e em toda circunstância que "a guerra é tecnicamente viável!". Esse registro se baseia na existência de uma vasta comunidade interpretativa que não somente contribuiu para a constituição das Forças Armadas nacionais, imprimindo às guerras estatais sua forma distintiva, como também, e sobretudo, tornou os conflitos armados tecnicamente pensáveis (DODIER, 1993b). ${ }^{5}$ É esse ponto de sustentação convencional, incontornável a qualquer decisão beligerante - mas também a outras escolhas tais como aquelas que dizem respeito à fabricação de armas ou à determinação de orçamentos de defesa - que nós tratamos 


\section{Christophe Wasinski}

como um "regime de expertise estratégica" (DODIER, 1993a). As pesquisas jornalísticas sobre a guerra do Iraque de 2003 expõem particularmente bem como esse regime de expertise é incorporado em negociações anteriores ao conflito (HERSH, 2006; WOODWARD, 2004). Com efeito, ilustram as formas pelas quais militares e dirigentes civis, ao discutir planos de guerra e sua viabilidade, mobilizaram e adaptaram esse regime de expertise, do qual resultou a operação Iraqi Freedom.

Não obstante, é preciso esclarecer que a preocupação fundamental deste artigo não é a questão da eficácia "física" ou "material" das práticas estratégicas, ${ }^{6}$ mas a investigação das dinâmicas pelas quais a crença na viabilidade técnica da guerra pôde impor-se. Em outras palavras, parafraseando uma expressão corrente na linguagem dos cientistas políticos, busca-se melhor compreender os mecanismos por meio dos quais a ideia estratégica, historicamente subjacente à instituição militar, conseguiu impor-se e sustentar-se "na agenda" social. Assim, o texto a seguir é também uma contribuição aos questionamentos acerca da normalização do uso da força militar graças à difusão de uma ideologia da viabilidade. ${ }^{7}$

O núcleo do regime de expertise estratégica encontra-se no pensamento estratégico dos militares, local por excelência de afirmação da viabilidade técnica. ${ }^{8}$ Mais especificamente, este estudo se concentra na análise dos discursos contidos no pensamento estratégico escrito. É, todavia, evidente que existe também uma reflexão estratégica oral. Não obstante, o aspecto estruturante da escrita nas sociedades europeizadas - que dão maior importância aos textos sob a forma de constituições, leis, regulamentos ou procedimentos - legitima a opção pela concentração no aspecto escrito (a partir do momento que é aceito que este não exaure o tema da construção do regime de expertise estratégica).

Por meio da análise desses escritos, é possível evidenciar não apenas uma "simples" narrativa histórica, mas sim aquilo que é de interesse 
fundamental deste artigo: os mecanismos mais ou menos gerais que contribuem amplamente para fundar e assegurar a reprodução desse famoso regime de expertise estratégica. ${ }^{9}$ Ademais, por limitação de espaço, o presente texto restringe a extensão dos discursos abordados, ${ }^{10}$ concentrando-se no pensamento militar terrestre produzido na Europa e nos Estados Unidos entre o fim da Idade Média e os dias atuais - novamente, devido ao seu poder estruturante. Decidiu-se, igualmente, não levar em consideração os campos da guerrilha, da guerra revolucionária, da luta de contrainsurgência etc., que são costumeiramente construídos pelos atores como uma expertise diferenciada da expertise estratégica dita "clássica". Além disso, por razões similares, apenas se sobrevoa o campo estratégico nuclear.

\section{Os Componentes do Quadro Interpretativo Estratégico Clássico}

O regime de expertise estratégica aparece entre o fim da Idade Média e o século XVII. É nesse momento que se constitui, de forma progressiva, um quadro interpretativo relativo à forma de conduzir as guerras modernas, a partir da experiência obtida nos diversos conflitos que opuseram as entidades políticas na Europa (tais como as guerras de Luís XIV). Destaca-se que o saber constituído nesse quadro contribui amplamente para a formação da guerra moderna - muito diferente daquela encontrada na Idade Média - ao fundar uma representação muito mais organizada e decisiva da utilização da violência. Tal saber participa da constituição da definição daquilo que é entendido pelo uso da palavra "guerra" no universo estatal moderno. Assim, cabe interrogar-se acerca dos modos de inscrição, objetivação e transmissão desse saber de modo a melhor entender como os atores conferem, pouco a pouco, por meio da reunião progressiva de elementos dispersos, do "micro ao macro", uma existência pública e um sentido socialmente aceito para a técnica da guerra (CHATEAURAYNAUD, 1991, p. 463). 


\section{Christophe Wasinski}

Durante o período considerado, a formação do regime de expertise estratégica apoia-se em dezenas de tratados militares técnicos e táticos - hoje devidamente inventariados por historiadores militares que evidenciam o retorno da infantaria mobilizada em dispositivos organizados (KLEINSCHMIDT, 1999; GONZALES DE LEON, 1996; HALE, 1985). O mais famoso desses textos é, sem dúvida, A arte da guerra, de Maquiavel (1982). O texto do autor florentino aproxima-se de diversos tratados redigidos por oficiais europeus muito menos conhecidos (Billon, de Gheyn, Rohan, Wallhausen). Para retomar os conceitos de Michel Foucault (1975), encontra-se, em todos esses textos, uma acumulação de saberes de tipo disciplinar centrados no soldado, individual ou em grupo(s) (ver a Figura 1, que re-

Figura 1

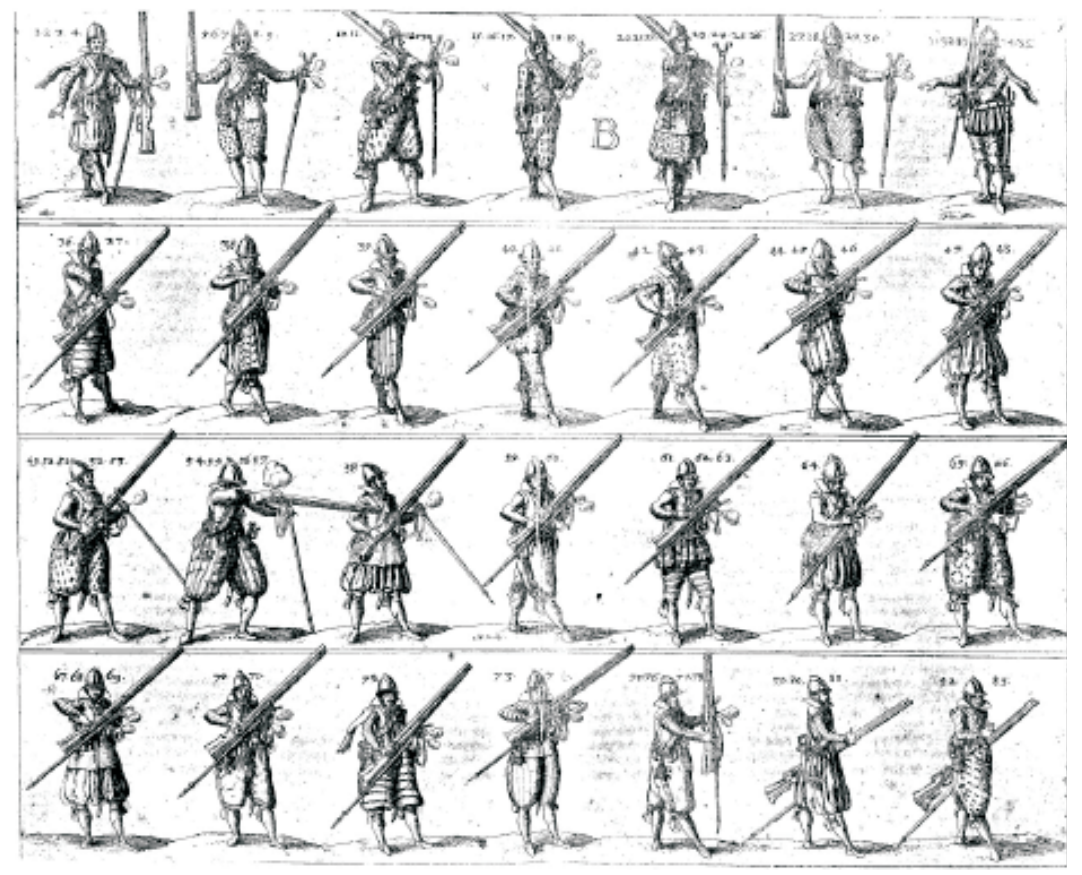

Fonte: WALLHAUSEN, J. L'art militaire pour l'infanterie. [Trad. do alemão]. Franeker: Balck, c. 1615. [s. p.]. [Representação nas páginas 8 e 9]. Disponível em: <gallica.bnf.fr>. Acesso em: jan. 2013. 
Validar a Guerra: A Construção do Regime de Expertise Estratégica

trata um soldado manipulando uma arma de fogo). Eles contêm, com efeito, diversas informações sobre como os homens devem ser treinados, mobilizados ou movidos em formações organizadas.

Ademais, encontra-se, nos mesmos textos, um vocabulário relativo às funções militares e à hierarquia (lanceiros, mosqueteiros, comandantes de batalhão, oficiais etc.). Como os historiadores militares demonstraram, o conjunto das obras tem inegáveis efeitos interpelativos (ou performativos) na construção dos soldados cuja função claramente definida nesses textos se torna um ideal normalizador. ${ }^{11}$ Finalmente, esse saber produz representações reificadas dos soldados mobilizados nos campos de batalha em ordens quadradas ou retangulares (ou, por vezes, em formas mais fantásticas, nem sempre efetivamente testadas em campanha) (JONES, 1999). Esses dispositivos conferem aos militares uma importante coesão, uma vez que, submetidos a um estreito controle pelos seus pares, são constrangidos a seguir com os ordenamentos.

Os homens assim vigiados são, portanto, capazes de levar a termo perigosas batalhas de aniquilação, que tomam o lugar das operações de assédio que parece ter sido a prática dos combatentes da Idade Média. Segundo pesquisas recentes, ainda que tal capacidade de destruição não se atualize igualmente a cada época, trata-se de uma etapa fundamental no desenvolvimento de uma cultura guerreira centrada sobre a destruição física do inimigo (HANSON, 1990; JOXE, 1991; KEEGAN, 1993).

A formação do quadro interpretativo sustenta-se, em seguida, em uma realização prática particular do saber técnico militar. Com efeito, a credibilidade de tal saber não é sustentada apenas pelo seu conteúdo, mas também pela forma como é expresso nos tratados militares que emergem no fim do medievo. (a) Em primeiro lugar, trata-se de um saber que é formalizado em forma impressa (MACLUHAN, 1967). O recurso a esse meio, muito favorecido pelo surgimento da 
imprensa no século XVI, é uma forma de estabilizar os conteúdos (a oralidade sendo caracterizada por sua maior flexibilidade) e de destacar o conhecimento da experiência corporal e do contexto social imediato (CERTEAU, 1975, p. 243-335 e p. 229-231; BARTHES, 1972, p. 18). A codificação escrita do saber militar é igualmente parte de uma lógica de fortalecimento burocrático (que contribui, ela mesma, para o desenvolvimento dos Estados europeus no final da Idade Média) (TILLY, 1975).

É preciso ressaltar, todavia, que a despeito de seu poder estruturante não se deve considerar ipso facto que o pensamento escrito esgota o domínio estratégico. (b) A linguagem utilizada nos tratados assume todos os contornos da tecnicidade. Não é uma escrita metafórica, poética ou romanesca; no mais das vezes, é precisa, estruturada e, tende-se a dizer, de difícil leitura. Destaca-se também que a maior parte dos títulos é de natureza remática (GENETTE, 1987). Com efeito, os títulos remetem diretamente ao status das obras Teoria da guerra, $\mathrm{A}$ arte da guerra, Memória sobre a guerra etc.

A transparência desses títulos prova sua vontade de pertencer a um gênero, uma comunidade de sentido. (c) O formato dos tratados é muito inspirado pelo saber dos engenheiros, que produzem planos de fortalezas e outros mapas de campanhas para os militares (POLLAK, 1991; DUFFY, 1979; 1985). De fato, os engenheiros legaram aos militares um pensamento "geometrizante" que serve de fio condutor narrativo espacial; as ações militares são narradas como eventos que se sucedem (ver Figura 2, que expõe a organização de unidades militares em "ordem oblíqua" no campo de batalha). Esse pensamento geométrico é também identificável no recurso a um vocabulário especializado (fronte, flanco, vanguarda etc.).

Esse conjunto de elementos permite ordenar o caos da batalha e tornar narrável e compreensível (ou, recuperando a expressão de Paul Ricoeur (1983-1985), "tecer a intriga") um conjunto de eventos que 


\section{Figura 2}

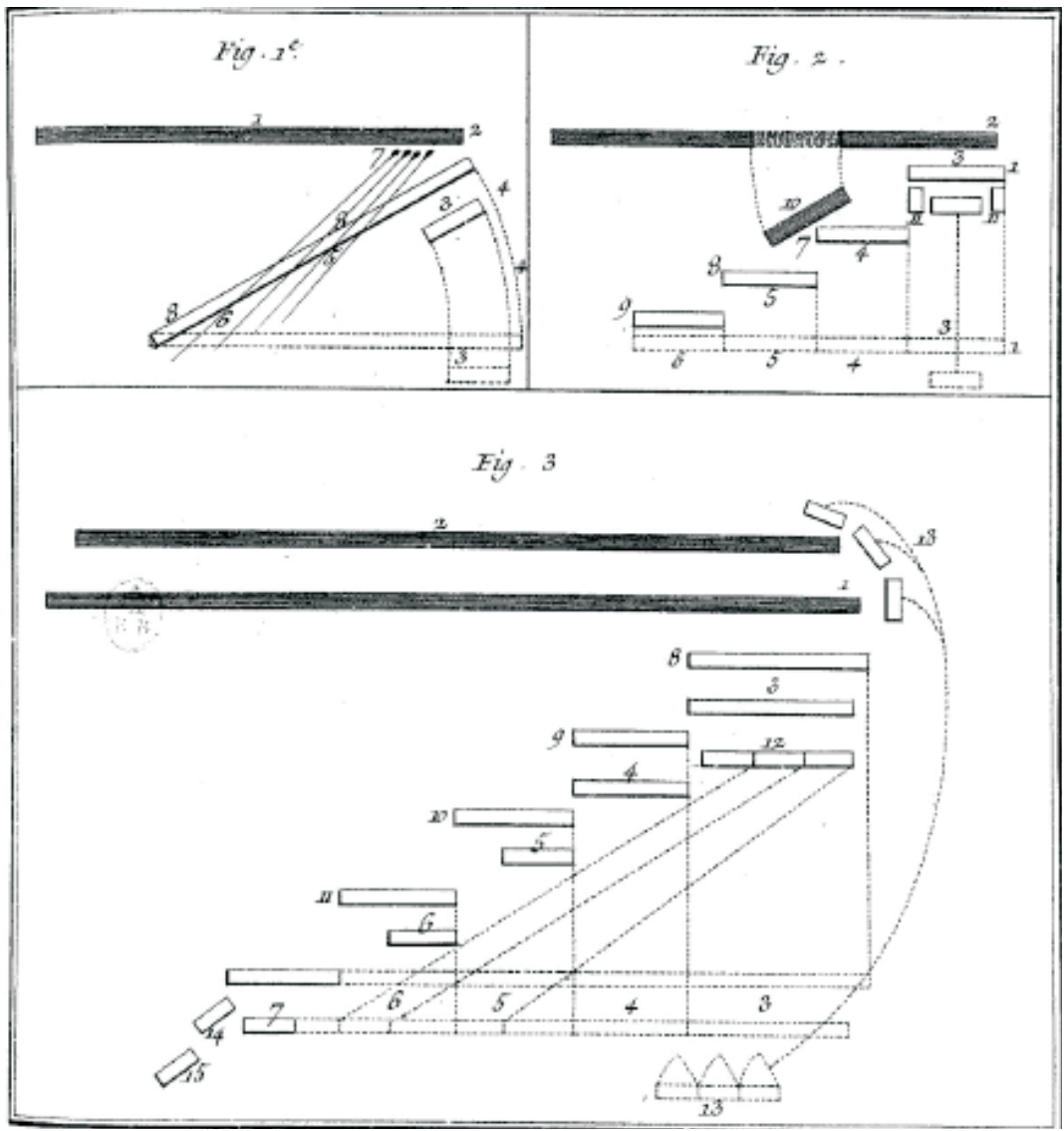

Fonte : DE GRIMOARD, Chevalier. Essai théorique et pratique sur les batailles. Paris: Dessains, 1775. [s.p.]. Disponível em: <gallica.bnf.fr>. Acesso em: jan. 2013.

ocorrem paralelamente. ${ }^{12}$ Constata-se, todavia, que o quadro geometrizante naturaliza a existência de um ponto de vista narrativo em detrimento de outras formas de narração. Assim, os relatos de guerra que assumem seu próprio elemento subjetivo (como aqueles de natureza autobiográfica, nos quais a vivência dos homens no terreno é apresentada) não são levados em consideração. O ponto de vista "cartográfico" daquele que sobrevoa, do alto, o campo de batalha pa- 
rece impor-se como o único olhar legítimo (PANOFSKY, 1975). Tal constatação se revela pertinente no âmbito da história militar "clássica" (dita "história de batalha"). Com efeito, é preciso considerar a história militar escrita pelos oficiais e para os oficiais como parte integrante do pensamento estratégico (nesse sentido, o gênero diferencia-se nitidamente dos escritos das antigas memórias militares, demasiadamente imprecisos sobre o desenvolvimento das ações militares) (BLOOM, 1994; COX, 1992; HARARI, 2004). A estrutura narrativa desses relatos e a dinâmica que perpassa seu desenvolvimento evoluem de forma muito similar àquela do pensamento estratégico teórico clássico.

Finalmente, a dinâmica textual em questão tem um papel fundamental no estabelecimento da linha divisória entre política e técnica. ${ }^{13} \mathrm{O}$ pensamento militar é parte da construção de uma dicotomia entre, de um lado, uma esfera política responsável pela decisão final com relação ao uso da violência e, de outro, uma esfera técnica regida pelos princípios militares, os quais são "impossíveis" de serem derrogados (ver adiante). Fica evidente nesse processo um elemento que marca a diferenciação entre esferas de atividades sociais em uma lógica durkheimiana (DURKHEIM, 1986). Não obstante, para além desse aspecto, é preciso destacar que o pensamento militar efetua um golpe: ele se outorga (ao menos parcialmente) o direito de determinar o limite da intervenção política no ato de guerra, considerando que a especificidade de sua ação se impõe de forma universal (simplificadamente: "a política tem o direito de iniciar o conflito, mas não tem nada a dizer quanto ao seu desenvolvimento no campo de batalha, algo que depende de regras que apenas os militares dominam").

Há indubitavelmente um elemento paradoxal nisso tudo: o universo militar, ao mesmo tempo em que afirma sua submissão "sincera e total" à política, busca impor um limite a tal submissão. Isso o carrega em direção ao discurso de Clausewitz e, provavelmente com mais substância, aos discursos sobre Clausewitz (por exemplo, as inter- 
Validar a Guerra: A Construção do Regime de Expertise Estratégica

pretações alemãs de Moltke e Ludendorff) (ARON, 1976). ${ }^{14}$ Esses remetem repetidamente ao traçar da fronteira entre o político e o militar, tal como é estabelecida primordialmente pelos militares. Tais debates servem igualmente para conferir uma legitimidade utilitária à guerra, ao fazer dela um instrumento incontornável da política.

O quadro interpretativo fornece conexões entre percepção e julgamento (prises) amplamente aceitas, a partir das quais os estrategistas dos séculos seguintes poderão, como será apresentado, ativar um trabalho intertextual de intercruzamento e institucionalização mais intenso. $^{15}$

\section{Confirmar a Eficácia Militar}

As bases do quadro estratégico clássico apresentadas acima não implicam que a fundamentação do regime de expertise estivesse adquirida de uma vez por todas; esse deve constantemente ser reativado para continuar a influenciar o curso dos eventos. Em outras palavras, os estrategistas devem lutar para manter viva nos espíritos a convicção de que "a estratégia funciona". Para tal, um trabalho discursivo de repetição e confirmação é rapidamente levado a termo pela comunidade dos estrategistas. Como mostra a história do pensamento estratégico, esse é um trabalho que (entre outros) foi particularmente bem realizado nos séculos XVII e XVIII a partir das obras sobre as guerras de Frederico II da Prússia, as guerras napoleônicas ou ainda as guerras de unificação alemã. ${ }^{16}$ Nesse âmbito, quatro modalidades devem ser destacadas.

De modo geral, o regime de expertise estratégica constrói-se a partir do quadro interpretativo de acordo com um mecanismo de intertextualidade (KRISTEVA, 1969). Segundo tal dinâmica, o fortalecimento do discurso opera-se de forma capilar, camada textual após camada textual, por meio do empréstimo e reinvestimento de ideias. De fato, a maior parte dos autores é levada a citar seus pares em diversas oca- 


\section{Christophe Wasinski}

siões, prática que se impõe no final da Idade Média. Nesse período, os textos organizavam-se de forma hierárquica de acordo com um "ponto central": a Bíblia. Tal centro fundamenta a autoridade e, portanto, a credibilidade, a veracidade e a realidade de todos os demais textos (COMPAGNON, 1979).

Após tal período, a autoridade bíblica apaga-se em diversos domínios. A autoridade última não mais recai sobre um "ponto central", mas sobre uma rede complexa de referências. Tal conjunto pode inclusive ser recortado dando conta de qual oficial se apoia em qual oficial nas obras fundamentais do regime de expertise estratégica. Ao ler Feuquières, encontram-se os nomes de Montecuculli, Folard, Coehoorn, Vauban etc. Ao ler Maizeroy, os nomes de Montecuculli, Feuquières, Puységur, Mesnil-Durand, de Saxe etc. Em Grimoard, aparecem Montecuculli, Puységur, Guischardt, Maizeroy etc. Em Mesnil-Durand, Montecuculli, Folard, Feuquières, Puységur, Guischardt, Maizeroy etc. Por sua vez, Puységur, Feuquières, Folard, Montecuculli são citados por Bosroger. A enumeração desses grandes nomes hoje em sua maioria esquecidos -, responsáveis por pensar os dispositivos adequados diante da generalização das armas de fogo e refletir acerca da organização militar europeia dos séculos XVIII e XVIII, pode parar por aqui: como se pode ver, o sistema de referências é denso.

Tal sistema contribui para dar credibilidade às afirmações militares técnicas contidas nas obras e está na origem de uma verdadeira comunidade interpretativa (FISH, 2007). Percebe-se, também, que as conexões intertextuais se baseiam em uma dupla mecânica. Por um lado, as conexões são feitas a partir de um procedimento individual. Os estrategistas (muitas vezes, mas não necessariamente, militares) tendem a mostrar-se "calculadores", fazendo com que seus textos coincidam com o estilo definido pelo quadro e correspondam ao máximo às expectativas do regime de expertise. Tal ponto foi claramente exposto nos trabalhos biográficos contemporâneos sobre o historia- 
Validar a Guerra: A Construção do Regime de Expertise Estratégica

dor e teórico militar Antoine de Jomini (1779-1869), por muito tempo considerado como um dos maiores intérpretes das operações napoleônicas (LANGENDORF, 2004). ${ }^{17}$

Com isso, maximizam suas chances de serem levados em considerações pelos seus pares e, assim, são mais facilmente integrados ao edifício estratégico. Por outro lado, a integração a esse domínio passa também pela aceitação, por parte dos pares, do texto produzido por este ou aquele estrategista. ${ }^{18}$ Trata-se, assim, de uma prova pela qual todo texto deve passar para poder fazer parte do regime de expertise e ver-se designado um lugar na estrutura intertextual. Com efeito, essa segunda etapa, que remete à lista de autores acima, é certamente mais importante que a primeira, uma vez que, a despeito da tentativa individual de se impor como um especialista a partir de uma posição voluntarista, a última palavra sobre o status de uma obra pertence ao edifício intertextual e, mais globalmente, ao lugar que lhe é historicamente atribuído.

A dinâmica intertextual organiza-se igualmente por meio de um duplo processo de dessingularização e ressingularização parcial (também chamado de "tradução") (DODIER, 1993a, p. 48, p. 91 ss., p. 267, p. 269; CALLON, 1986). O regime de expertise estratégica tem por ambição criar um saber técnico formal cuja pretensão de validação ultrapassa o caso individual. Para tal, ele precisa agir dessingularizando cada evento. É assim que um pensador tão importante quanto Jomini é capaz de comparar uma guerra do século XVIII com uma guerra do século XIX (e inversamente) a despeito de não serem mais os mesmos homens, as mesmas motivações, nem os mesmos locais a serem invocados e, em seguida, estabelecer "princípios da guerra" cuja validade é considerada universal. ${ }^{19}$ A dessingularização permite não apenas produzir elementos comparáveis, como também serve de ponto de apoio para um pensamento estratégico entendido como científico e, portanto, fundamentado em recorrências previsíveis. 


\section{Christophe Wasinski}

Em um segundo momento, porém, ocorre um trabalho de ressingularização. Com efeito, todo estrategista se inspira nos ditos de seus pares, mas nunca repete, palavra por palavra, suas afirmações. Com efeito, os estrategistas dispõem de certa latitude, o que lhes permite reintroduzir a singularidade na dessingularização. É por meio desse processo, notadamente, que o edifício intertextual foi capaz de explicar e incentivar a mudança de escala da guerra. A dilatação dos espaços de combate e o aumento dos efetivos militares serão progressivamente traduzidos no pensamento militar sem qualquer contestação por parte do quadro interpretativo inicial. Tal quadro vê-se adaptado em função do uso do mesmo vocabulário, dos mesmos conceitos, das mesmas concepções.

Outros termos são, outrossim, elaborados, para serem subsequentemente integrados ao edifício: fala-se, por exemplo, de grande tática, de arte operatória, de operativo ou ainda de nível operacional da guerra para fazer referência àquilo que se interpõe entre a tática e a estratégia. Mas trata-se mais de adaptação do que de questionamento, e o pensamento estratégico sempre busca maneiras de impor sua vontade por meio do uso decisivo da força contra o inimigo. Percebe-se, ademais, que, durante esse processo, o distanciamento com relação ao corpo do soldado é cada vez mais importante; os indivíduos anônimos dos primeiros tratados disciplinares deram lugar a grupos genéricos que são igualmente reificados (entre outras técnicas, esses grupos são representados em esquemas cartográficos cada vez mais globais).

É muitas vezes difícil não identificar, nesse processo, uma dinâmica de autonomização da linguagem que parece não mais dar conta da experiência dos homens no campo, remetendo, sobretudo, à evolução da experiência de oficiais em quartéis distantes do fronte (LATOUR, 1991, p. 91). Finalmente, tal dinâmica (que podemos encontrar nos escritos de Bülow, Lloyd, Jomini, Clausewitz, Moltke, 
Schlieffen, Colin, Camon etc.) contribui para o caminhar em direção à guerra total.

Em seguida, a dinâmica intertextual apoia-se sobre a institucionalização das Forças Armadas. Desde o fim da Idade Média, estas se transformaram em sólidas instituições burocráticas e hierarquizadas. Todavia, é apenas ao longo do século XIX que esse processo atinge sua plena maturidade (BUCHOLZ, 1991; REARDON, 1990; GRIFFITH, 1989; NENNINGER, 1978; BOND, 1972; LUVAAS, 1964). A natureza intertextual do processo não desaparece nesse contexto. De fato, se os discursos estratégicos conferem uma justificativa a essas instituições, o inverso é igualmente verdade; importantes discursos encontram-se reforçados pela presença das instituições. Em outras palavras, as instituições tornam-se um elo para sustentar a malha do saber especializado (DODIER, 1993a, p. 145). Por conseguinte, os exércitos modernos não cessam de professar sua fé no valor técnico da violência por meio de regulamentos ou manuais técnicos, táticos e operacionais, de textos dedicados à formação dispensadas nas novas escolas de oficiais (um dos mais famosos sendo The Operations of War Explained and Illustrated de Burce Hamley (1878), que foi reeditado em diversas ocasiões e serve de obra de referência não apenas na Inglaterra, como também nos Estados Unidos) ou ainda nas numerosas revistas militares que começam a aparecer no século XIX: a Militär-Wochenblatt; a Militär-Literatur-Zeitung (1819); o Zeitschrift für Kunst, Wissenschaft und Geschichte des Krieges (1822); o Bulletin des Sciences Militaires (1824); o Journal des Sciences Militaires (1825); o Spectateur Militaire (1826-1829, 1842-1843); a Revue Militaire - Journal des Armées de Terre et de Mer (1833-1834); a France Militaire (1845); a Preussische Wehr-Zeitung (1848); o Moniteur de l'Armée (1840-1841, 1847, 1849-1850); a Revue Bibliographique Militaire (1852); o Bulletin Militaire de l'Étranger (1871) etc. (GAT, 2001, p. 64-65). ${ }^{20}$ 
Além disso, seria impossível deixar de lado o impacto da constituição dos planos de guerra nessa mesma dinâmica. Efetivamente, é também a partir do século XIX e do começo do século XX que os Estados-maiores dos grandes Estados europeus começam a preparar sistematicamente planos de guerra para a eventualidade de conflitos com seus vizinhos (o mais famoso deles sendo certamente o plano Schlieffen, por meio do qual as forças alemãs iniciaram as operações militares da Primeira Guerra Mundial). ${ }^{21}$ Esses planos, em sua maior parte elaborados a partir de uma intertextualidade burocrática (mas também com a ajuda de simulações operacionais e de diversas discussões), conta, entre outros, com elementos relacionados à logística e aos meios necessários para mobilizar e deslocar as centenas de milhares de soldados então alistados nos exércitos alemão, austríaco, estadunidense, francês ou russo.

Fica claro que a constituição desses planos militares contribui amplamente para a formação e o fortalecimento do regime de expertise estratégica. Percebe-se, igualmente, que um grande número das dinâmicas burocráticas elaboradas nessa passagem depende do apagamento dos traços da constituição do mesmo regime. Na realização dos regulamentos, dos manuais ou dos planos, a instituição tende a fazer desaparecer a presença dos indivíduos (diversos textos são, inclusive, anônimos) que fundam o regime de expertise para substituí-los pela personalidade de uma instituição de contornos monolíticos e difícil questionamento de um ponto de vista antropológico (BOLTANSKI, 2009). Nesse sentido, vemos emergir um pensamento estratégico cada vez menos "artesanal", mas sempre ligado ao quadro interpretativo clássico.

Finalmente, é preciso notar que a maioria dos tratados militares publicados à época não eram secretos (com algumas poucas exceções, tais como os textos do soberano Frederico II, que seriam, não obstante, rapidamente divulgados) (LUVAAS, 1966). Daí resulta que, a despeito da nacionalização das Forças Armadas, sobretudo a partir do século XIX, a expertise estratégica circula amplamente pela Euro- 
pa e fora dela. Há muito tempo, as obras militares viajam primeiro pela Europa e, em seguida, pelo resto do mundo. As traduções desses textos são, ademais, cada vez mais numerosas. Os oficiais, por sua vez, são acostumados a viajar para sua própria formação ou para contribuir à de seus pares, participando assim da circulação do saber estratégico.

Além disso, Forças Armadas enviam, ocasionalmente, observadores ao lado de outras Forças em combate. Estes são, por vezes, a fonte de incorporação de experiências publicadas sob a forma de livros, relatórios ou artigos (assim, os oficiais europeus interessavam-se, por exemplo, pela guerra civil americana, mesmo se as lições de lá tiradas permanecessem limitadas a questões técnicas) (LUVAAS, 1959). Os militares podem também acompanhar indiretamente o curso de operações de guerra por meio da mídia. Por fim, oficiais publicam regularmente relatórios de operações estrangeiras em revistas especializadas. Assim, fica claro como a malha intertextual conta com uma difusão de tipo transnacional.

Em seus trabalhos sobre a memória e a história, Paul Ricoeur (2000, p. 70, p. 105 ss.) evoca a existência de uma "memória-hábito", relativamente espontânea, e de uma "memória-obrigada", sustentada pela formação dos espíritos. À luz dos elementos apresentados até agora, o regime de expertise estratégica, sustentado sobre a conexão das experiências pela via intertextual, corresponde majoritariamente a uma memória de obrigação. Naturalmente, tal fato se deve fundamentalmente ao enraizamento institucional desse saber. Não obstante, a despeito da existência de mecanismos complexos e mais ou menos institucionalizados de formação e repetição, o edifício estratégico, como será exposto, não está imune a críticas.

\section{Dos Testes de Validação}

Efetivamente, a expertise estratégica é regularmente alvo de críticas de origens diversas (e das quais, mais uma vez, apenas as modalida- 
des intertextuais serão levadas em consideração no presente estudo) que representam testes aos quais deve fazer frente. Assim, na segunda metade do século XIX e no século XX, particularmente no contexto da Guerra de Secessão, das duas Guerras dos Bôeres, da Guerra Russo-Japonesa, das duas Guerras Mundiais e da Guerra Fria, o regime de expertise estratégica fez face a três grandes categorias de críticas às quais respondeu de maneiras distintas (BOLTANSKI, 2009; LATOUR, 2006, p. 15-24).

Em primeiro lugar, enfrentou críticas que foram respondidas pelo silêncio (o que constitui formalmente uma rejeição do teste enquanto digno desse nome). Tal atitude parece poder explicar-se de duas formas (DODIER, 1993a, p. 228 ss.). (a) Por um lado, por pouco que sua existência seja materialmente conhecida, o que nem sempre ocorre, a crítica é julgada como não pertinente; ela não merece ser levada em consideração, pois sua voz é tida como substancialmente discordante ou formalmente incompatível com o regime. Esse ponto é ilustrado pela constante rejeição das contestações fundamentadas abertamente sobre a expressão das subjetividades, como entre os romanos (sobre esse tema, podemos pensar em Le feu, de Henri Barbusse (1917), ou A l'Ouest rien de nouveau, de Ericha Maria Remarque (1988)), sendo o campo da subjetividade dificilmente reconciliável com o viés tecnicista do regime de expertise.

Existe, ademais, uma rejeição, já bem conhecida, ligada à substância da argumentação das críticas radicais formuladas pelos pacifistas (com efeito, é possível estudar extensivamente o pensamento estratégico sem jamais encontrar referência a essa perspectiva). Tais rejeições tendem a provar que o regime de expertise estratégica goza de uma autonomia mínima. (b) Mesmo que isso seja difícil de provar explicitamente, pode-se suspeitar que o edifício estratégico deixa de levar em consideração certas críticas não em função de seu distanciamento, mas por razões mais calculistas: engajar-se com uma crítica envolve reconhecer sua existência e sua potencial pertinência. 
Validar a Guerra: A Construção do Regime de Expertise Estratégica

Assim, equivale a se tornar eco dessa crítica, dando-lhe mais força. De toda forma, nos dois casos evocados, há uma rejeição do desafio aberto, algo que o regime de expertise estratégica pode se permitir naquelas instâncias em que se apresenta mais seguro de si. Note-se, todavia, que, em determinados casos, a crítica pode ser considerada como distanciada e, ainda assim, não fazer frente a tal muro de silêncio.

A história do pensamento estratégico não contém, todavia, um número expressivo desses casos. O mais exemplar deles é provavelmente aquele do banqueiro liberal e pacifista polonês Jean de Bloch. Bloch havia publicado, em 1898, um tratado levantando a questão da possibilidade da guerra (ECHEVARRIA, 2000, p. 85 ss.; TRAVERS, 1979). Nele, percebia a dificuldade em levar adiante guerras em uma época na qual as forças destrutivas haviam aumentado substancialmente. O interesse que o pensamento estratégico lhe prestou era certamente fruto da capacidade de tal analista civil de interpretar dados técnicos militares. Donde a utilidade, para os militares, em engajar-se com o questionamento de Bloch para, em seguida, relativizar sua força crítica.

Em segundo lugar, o regime de expertise pode ser submetido a críticas internas, ou seja, críticas que são formuladas dentro do quadro reconhecido pelo edifício estratégico. Tais críticas - comumente transformadas em controvérsias - não podem simplesmente ser tratadas com silêncio, sob o risco de incoerências irremediáveis emergirem no centro do regime, podendo, em última instância, colocar sua existência em questão (LATOUR, 2005, p. 87-111). Assim, entre a segunda metade do século XIX e a véspera da Segunda Guerra Mundial, emergiram séries de controvérsias acerca do grau de iniciativa que devia ser outorgado aos comandantes de grandes batalhões militares em campanha (Bernhardi, Boguslawski, Freytag-Loringhoven, Von de Goltz etc.), do uso de dispositivos de infantaria em formação compacta ou dispersa no contexto do aumento do poder de fogo (Ardant 


\section{Christophe Wasinski}

du Picq, Bonnal, Foch etc.) ou do uso de blindados e meios aéreos operando de forma independente ou subordinada às demais Armas (De Gaulle, Douhet, Fuller, Kingston-McCloughtry, Martel, Mitchell, Volckheim etc.). ${ }^{22}$

O acompanhamento detido dessas controvérsias (cujo conteúdo preciso escapa ao escopo deste trabalho) revela que em nenhum caso a opção da possibilidade do uso da força em tempos de guerra é questionada. Com efeito, elas operam como uma forma de manter a crítica dentro dos limites da ortodoxia estratégica. Ademais, aquém de fazerem nascer instâncias de questionamento revolucionário do pensamento estratégico, essas controvérsias fazem emergir a existência de uma válvula de escape intelectual. Os atores dos debates, de fato, não cessam de repetir que a estratégia "é possível, sob a condição de...". E esse "sob a condição de..." se traduz em uma reflexão sobre os meios de ajuste técnicos. O discurso consiste, portanto, em afirmar que: é possível, sob a condição de melhorar o moral da infantaria de modo a incitá-la a investir contra a trincheira inimiga (mesmo esta sendo defendida por metralhadoras); é possível, sob a condição de utilizar veículos blindados de forma concentrada ao invés de apenas como suporte à infantaria; é possível, sob a condição de atacar o flanco e não a vanguarda do efetivo inimigo; é possível, sob a condição de esgotar as forças inimigas de antemão de modo a diminuir o moral das tropas; etc.

Tais discussões de fato tendem a tornar o regime de expertise um núcleo duro, um ponto de partida aceito por todos quando das controvérsias, cercado de camadas mais ou menos macias no meio das quais são levadas adiante as justas intelectuais a partir das quais possíveis ajustes emergem. Nota-se, além disso, que uma parte importante desses ajustes, notadamente no século $\mathrm{XX}$, diz respeito à integração de elementos materiais (armas automáticas, carros ou aviões de combate, helicópteros etc.). Uma vez mais, as controvérsias materiais não levantam a questão de "saber se" a estratégia ainda é possível dado que existem, por exemplo, metralhadoras, mas sim de "saber como" 
fazer a estratégia uma vez que tais armas existem. Em suma, a questão da impossibilidade estratégica é cuidadosamente afastada das controvérsias militares. No final, tais controvérsias não enfraquecem seriamente o regime de expertise estratégica.

De fato, pode-se pensar que elas contribuem para o seu fortalecimento graças à crescente densidade da literatura estratégica, conectando-se ao edifício intertextual preexistente. Em outros termos, os autores da controvérsia, a despeito de suas discordâncias particulares, reafirmam constantemente sua crença no regime de expertise cada vez que publicam um documento sobre o uso de metralhadoras, de carros, de aviação, de gases de combate ou mesmo, por vezes, de armas nucleares. Sob essa perspectiva, pode-se apreender o regime de expertise como uma espécie de instância jurídica suprema que constrange os atores a pensar de uma forma que é tudo menos livre, uma vez que não podem nunca dizer publicamente: "é impossível". Pouco importa o número de vítimas, a amplitude das destruições materiais, os efeitos desestabilizadores no plano social, econômico ou psicológico (ou ainda, simplesmente, a opinião do soldado de infantaria tomado individualmente e que pensa que é, de fato, impossível): o consenso estabelecido deve ser mantido.

Ao lado das críticas que provocam ajustes internos, existem críticas que conduzem a necessários reenquadramentos quanto à extensão do domínio de expertise. As críticas em questão afirmam que a guerra é de fato possível, sob a condição de estender ou reduzir seu domínio de atuação. Assim, no primeiro caso, a extensão do domínio de validação da guerra pode levar a repensar o funcionamento político, social, econômico, científico, moral etc. das sociedades. O discurso estratégico engaja, portanto, bem mais do que somente a comunidade estratégica.

Historicamente, observa-se um exemplo desse fenômeno no pensamento estratégico alemão do início do século XX, com autores como 
Bernhardi, Von der Goltz e, sobretudo, Ludendorff, quando este trata da guerra total (ARON, 1976). Apesar da catástrofe humana, social e política que constituiu a Primeira Guerra Mundial, Ludendorff jamais coloca em questão a opção estratégica. Em vez disso, o autor não cessa de denunciar a falta de vontade de tudo aquilo que não é militar. A mensagem é clara: a guerra é sempre possível, sob a condição de que o conjunto da sociedade (o olhar de Ludendorff incide, particularmente, sobre a falta de vontade dos civis) se submeta à lógica estratégica. Dito de outra forma, de acordo com Ludendorff e seus discípulos, o custo da manutenção do regime estratégico é o militarismo, o que implicaria uma profunda revisão do conjunto da sociedade.

O caso contrário também é possível. Os autores, reconhecidos ou não como membros da comunidade de expertise, podem interpelar o regime tendo em vista a proposição de um reenquadramento reduzido de seu domínio de validação. Assim, após a Primeira Guerra Mundial, uma série de comentadores voltou-se para explicar que o emprego racional e instrumental da força "é possível, sob a condição de que 'diminuamos nossas expectativas"”. Mais concretamente, para inúmeros estrategistas, a continuidade do regime de expertise implicava considerar a guerra sob um prisma mais defensivo ou dissuasivo (ODOM, 1999; DOISE; VAÏSSE, 1992; HIGHAM, 1966). Para alguns desses comentadores, de maneira caricatural, seria possível continuar a pensar as operações militares, mas apenas sob a égide de uma linha Maginot ou graças à presença de uma ameaçadora frota aérea.

Tal atitude é igualmente perceptível na Guerra Fria, no que concerne às armas nucleares. $\mathrm{O}$ advento destas últimas tende a reduzir a validez da opção estratégica, mas sem jamais contestar suas suposições centrais (HEUSER, 1997; STEINER, 1991; BAYLIS; GARNETT, 1991; HERKEN, 1987; KAPLAN, 1983; FREEDMAN, 1981; GARTHOFF, 1952). Os estrategistas nucleares (Brodie, Halperin, 
Validar a Guerra: A Construção do Regime de Expertise Estratégica

Kaufmann, Kissinger, Osgood, por exemplo) não questionam a validação técnica do regime estratégico. O que alguns deles colocam em evidência (particularmente entre os estrategistas da OTAN) é o fato de que o referido regime corre o risco de conduzir a um intercâmbio nuclear generalizado entre o Oriente e o Ocidente, o qual tornaria impertinente a opção estratégica clássica.

Para esses mesmos estrategistas, a opção estratégica clássica permanece válida, mas dentro de certas condições, por exemplo, a condução de guerras que eles denominam "limitadas". Por fim, pode-se entender sob uma mesma ótica aqueles textos jurídicos ou metajurídicos que impõem ao regime de expertise estratégico a proibição do recurso a determinados tipos de armamento (gás de combate, armas bacteriológicas, minas antipessoais etc.) com base na ideia de humanidade (BEST, 1980). Da mesma forma, esse discurso visa limitar a zona de ação do regime de expertise sem, no entanto, contestar o seu núcleo. Dito de outro modo, a superação do teste crítico pode implicar, para o regime de expertise, uma redução de seu domínio de validação.

De fato, o acompanhamento dos desdobramentos históricos do regime de expertise estratégico leva à admissão de que este se mostra não somente conservador, mas também bastante hábil quanto à sua capacidade de fazer frente aos testes impostos pela crítica. Esse regime está certamente pronto a debater diversos aspectos, mas a discussão não coloca em questão seus fundamentos (independentemente do custo para a sociedade, conforme mostrado pelas duas Guerras Mundiais, por exemplo) relativos ao uso técnico da força.

$$
\text { **** }
$$

Este artigo buscou colocar sucintamente em evidência os principais mecanismos que fundam o regime de expertise estratégico entre o fim da Idade Média e a Guerra Fria. Esse regime encontra sua origem em um edifício intertextual que contribui para conferir forma e defi- 


\section{Christophe Wasinski}

nir a guerra. Mais do que isso, tal regime contribui, em larga medida, para a expansão da ideia de que "a estratégia funciona". Assim, continua a desempenhar um papel essencial nas negociações sociais que podem conduzir à decisão de entrar em guerra. Afirma-se, portanto, que esse regime constitui um ponto de apoio convencional necessário à elaboração de um consenso sobre o tema; e, ainda, que normaliza a prática da guerra. Também se nota que a solidez do regime em questão é reforçada a cada dia pelas decisões políticas - tácitas ou explícitas - de manter as Forças Armadas e seus orçamentos. Por esse viés, uma caução é incorporada ao conjunto do edifício. É preciso considerar, ainda, que esse regime de expertise está longe de ser monolítico: ele é atravessado por numerosos conflitos - os quais não foram sublinhados o bastante aqui -, entre autores e escolas de pensamento. No entanto, como sugerido, tais oposições nunca colocam em questão a possibilidade técnica que constitui a opção estratégica. Sob esse ponto de vista, o edifício revela-se munido de capacidades reflexivas muito limitadas.

Finalmente, é preciso desconfiar do aporte concreto desse regime de expertise para as práticas de guerra mais precisas. A precisão do pensamento estratégico escrito no conforto dos escritórios nem sempre está de acordo com a vivência prática no campo, muito pelo contrário. Assim, é importante indagar-se a respeito da fidelidade dos porta-vozes - os comentadores estratégicos - sobre o que vivenciam os militares. As categorias operacionais, tão claras no papel, podem não resistir ao teste do campo de batalha. Ademais, também é preciso se questionar sobre a pertinência outorgada pelos atores no campo de batalha ao edifício intertextual e sobre o que aqueles últimos fazem deste em seu cotidiano de guerra (aceitação “em bloco", rejeição parcial, adaptação maior ou menor). Há, nessas questões, material para investigações a serem conduzidas sobre um modo mais antropológico (e oral), com vistas a compreender os métodos de apropriação local do edifício colocado em evidência neste trabalho. ${ }^{23}$ 


\section{Notas}

1. Admitindo, não obstante, que pesquisas suplementares permitiriam certamente fazer emergir a extensão de tal legitimidade em outras esferas, inclusive a civil.

2. As abordagens cognitivas, construtivistas e pós-estruturalistas, todavia, avançaram substancialmente naquilo que diz respeito à produção de representações que levam a políticas beligerantes. Ver, por exemplo, Lindemann (2008), Campbell (1998), Shapiro (1997) e Jervis (1988).

3. O trecho a seguir inspira-se em Boltanski (1991) e Latour (2005).

4. O trabalho clássico de Allison (1971) já apresenta uma primeira ilustração desse processo de negociação.

5. No âmbito dos estudos de segurança, ver Wazinski (2009) e Dumoulin e Wazinski (2010).

6. Sobre essa distinção, ver também Latour (2009) e Hacking (2001).

7. Para um questionamento central da abordagem dita de cultura estratégica, ver Johnston (1995). Sobre normalização e anormalização, ver Foucault (2003; 1972).

8. Como será exposto, nos distanciamos todavia dos trabalhos "clássicos" dos estudos de segurança acerca do pensamento estratégico e das doutrinas militares (Kier, Posen, Snyder etc.) entre outros, uma vez que estes consideram, no mais das vezes, a existência da instituição militar como uma variável independente. Para uma síntese dessas abordagens, ver Wasinski (2003).

9. Nesse sentido, a presente análise não tem nenhuma pretensão enquanto descrição histórica do pensamento estratégico. Para uma introdução à história desse pensamento, ver, por exemplo, Gat (2001) e Coutau-Begarie (1999).

10. Note-se que, além das obras históricas citadas em notas de rodapé ao longo deste artigo, a presente pesquisa levou à consulta de um corpo de mais de cem textos militares antigos (do século XVI a 1945). Por questões de espaço, essas obras não podem ser citadas aqui. Elas possuem, todavia, um papel essencial no desenvolvimento do raciocínio proposto.

11. De um ponto de vista mais geral, sobre esse tipo de dinâmica, ver Butler (1999).

12. Acerca da construção das narrativas, ver também Lyotard (1979). 


\section{Christophe Wasinski}

13. Emprestamos esse conceito de Latour (1991), em sua releitura de Schaffer e Shapin (1993).

14. Sobre Ludendorff, ver discussão mais adiante neste artigo. Os comentários sobre Clausewitz são abundantes na literatura sobre o pensamento estratégico e sua história. Por esse motivo, preferimos nos abster, aqui, de ir adiante sobre esse autor para nos aprofundarmos em elementos geralmente deixados de lado no campo dos estudos estratégicos e de segurança.

15. Sobre o conceito de prises, ver Bessy e Chateauraynaud (1995).

16. Para mais informações históricas, ver Queloz (2009), Colson (2006), Eysturlid (2000), Colson e Coutau-Begarie (2000), Colson (1999; 1993), Duffy (1988), Chagniot (1997), Paret (1986), Poirier (1985), Rothenberg (1981), Earle (1980), Ross (1979), Paret (1976), Howard (1965), Carrias (1960; 1948) e Caemmerer (1907).

17. Um exemplo mais recente dessa questão pode ser encontrando em Mearsheimer (1988).

18. Sobre esse assunto, ver também Foucault (2001).

19. Jomini não é o inventor desses princípios, mas fortalece em muito a sua legitimidade (ALGER, 1982).

20. Ver também Goltz (1890, p. 265), Dany (1912, p. 611-624), Griffith (1989, p. 62).

21. Para mais detalhes sobre os planos de guerra, ver Kennedy (1979), Tunstall (1993) e Zuber (2002). Vale notar, todavia, que a existência de um verdadeiro plano Schlieffen vem sendo questionada por parte da historiografia.

22. Sobre esse tema, ver Johnson (2003), Habeck (2003), Frieser (2005), Echevarria (2000), Winton e Mets (2000), Gudmundsson (1995), Griffith (1994), Corum (1992) e Larson (1984).

23. Para uma reflexão sobre esse assunto, ver Corcuff (1991). Para uma aplicação do "método antropológico" (no sentido amplo) no universo da guerra, ver, por exemplo, Thiéblemont (2001), Mauss-Copeaux (1998) e Doubler (1994). 


\section{Referências}

Bibliográficas

ALGER, J. I. The Quest for Victory - The History of the Principles of War. Londres: Greenwood, 1982.

ALLISON, G. T. Essence of Decision - Explaining the Cuban Missile Crisis. Boston: Harper Collins, 1971.

ARON, R. Penser la guerre - Clausewitz. 2 vol. Paris: Gallimard, 1976.

BARBUSSE, H. Le feu. Paris: Flammarion, 1917.

BARTHES, R. Le degré zéro de l'écriture. Paris: Seuil, 1972.

BAYLIS, J.; GARNETT, J. (Org.). Makers of Nuclear Strategy. Londres: Pinter, 1991.

BESSY, C.; CHATEAURAYNAUD, F. Experts et faussaires - Pour une sociologie de la perception. Paris: Métaillié, 1995.

BEST, G. Humanity in Warfare. Nova Iorque: Columbia University Press, 1980.

BLOOM, J. History, Military. In: MARGIOTTA, F. D. (Org.). Brassey's Encyclopedia of Military History and Bibliography. Londres: Brassey's, 1994. p. 475-497.

BOLTANSKI, L. De la justification - Les économies de grandeur. Paris: Gallimard, 1991.

_ De la critique - Précis de sociologie de l'émancipation. Paris: Gallimard, 2009.

BOND, B. The Victorian Army and the Staff College 1815-1914. Londres: Eyre Methuen, 1972.

BUCHOLZ, A. Moltke, Schlieffen, and Prussian War Planning. Nova Iorque: Berg, 1991.

BUTLER, J. Gender Trouble - Feminism and the Subversion of Identity. Londres: Routledge, 1999. 


\section{Christophe Wasinski}

CAEMMERER, R. von. L'évolution de la stratégie au XIXe siècle. Paris: Fischbacher, 1907.

CALLON, M. Eléments pour une sociologie de la traduction - la domestication des coquilles Saint-Jacques et des marins pêcheurs dans la baie de Saint-Brieuc. L'Année Sociologique, v. 36, p. 169-208, 1986.

CAMPBELL, D. Writing Security - United States Foreign Policy and the Politics of Identity. Minneapolis: University of Minnesota Press, 1998.

CARRIAS, E. La pensée militaire allemande. Paris: Presses Universitaires de France, 1948. 1960 .

La pensée militaire française. Paris: Presses Universitaires de France,

CERTEAU, M. De. L'écriture de l'histoire. Paris: Gallimard, 1975.

CHAGNIOT, J. Le chevalier de Folard - la stratégie de l'incertitude. Monaco: Editions du Rocher, 1997.

CHATEAURAYNAUD, F. Forces et faiblesses de la nouvelle anthropologie des sciences. Critique, n. 529-530, p. 459-478, jun.-jul. 1991.

COLSON, B. La culture stratégique américaine - L'influence de Jomini. Paris: Fondation pour les Études de Défense Nationale, 1993.

. L'art de la guerre de Machiavel à Clausewitz. Namur: Presses Universitaires de Namur, 1999.

Le général Rogniat, ingénieur et critique de Napoléon. Paris: Economica, 2006.

; COUTAU-BEGARIE, H. (Org.). Pensée stratégique et humanisme de la tactique des Anciens à l'éthique de la stratégie. Paris: Economica, 2000.

COMPAGNON, A. La seconde main ou le travail de la citation. Paris: Seuil, 1979.

CORCUFF, P. Eléments d'épistémologie ordinaire du syndicalisme. Revue Française de Science Politique, v. 41, n. 4, p. 190-209, ago. 1991.

CORUM, J. S. The Roots of Blitzkrieg - Hans von Seeckt and German Military Reform. Lawrence: University Press of Kansas, 1992. 
Validar a Guerra: A Construção do Regime de Expertise Estratégica

COUTAU-BEGARIE, H. Traité de stratégie. Paris: Economica, 1999.

COX, G. P. Of Aphorisms, Lessons, and Paradigms: Comparing the British and German Official Histories of the Russo-Japanese War. The Journal of Military History, v. 56, n. 3, p. 389-402, jul. 1992.

DANY, J. La littérature militaire d' aujourd'hui. La Revue de Paris, abr. 1912.

DODIER, N. L'expertise médicale - essai de sociologie sur l'exercice du jugement. Paris: Métailié, 1993a.

. Les appuis conventionnels de l'action - eléments de pragmatique sociologique. Réseaux, n. 62, p. 63-86, nov.-dez. 1993 b.

DOISE, J.; VAÏSSE, M. Politique étrangère de la France - diplomatie et outil militaire 1871-1991. Paris: Imprimerie Nationale, 1992.

DOUBLER, M. Closing with Enemy - How GIs Fought the War in Europe, 1944-1945. Lawrence: University Press of Kansas, 1994.

DUFFY, C. Siege Warfare - The Fortress in the Early Modern World 1494-1660. Londres: Routledge \& Kegan Paul, 1979.

The Fortress in the Age of Vauban and Frederick the Great 1660-1789 - Siege Warfare, Volume II. Londres: Routledge \& Kegan Paul, 1985 .

The Military Experience in the Age of Reason. Nova Iorque: Atheneum, 1988.

DUMOULIN, A.; WAZINSKI, C. Justifier l'arme nucléaire. Le cas français pendant les années 1990. Etudes Internationales, v. XLI, n. 1, p. 79-96, mar. 2010 .

DURKHEIM, E. De la division du travail social. Paris: Presses Universitaires de France, 1986.

EARLE, E. M. (Org.). Les maîtres de la stratégie. 2 vol. Paris: Flammarion, 1980.

ECHEVARRIA, A. J. After Clausewitz - German Military Thinkers Before the Great War. Lawrence: University Press of Kansas, 2000. 


\section{Christophe Wasinski}

EYSTURLID, L. W. The Formative Inluences - Theories, and Campaigns of the Archiduke Carl of Austria. Londres: Greenwood, 2000.

FISH, S. Quand lire c'est faire - l'autorité des communautés interprétatives. Paris: Les Prairies Ordinaires, 2007.

FOUCAULT, M. Histoire de la folie à l’âge classique. Paris: Gallimard, 1972 .

Surveiller et punir - naissance de la prison. Paris: Gallimard, 1975.

Qu'est-ce qu'un auteur? In:

. Dits et écrits, 1954-1975. vol. I. Paris: Gallimard, 2001. p. 817-837.

. Naissance de la clinique. Paris: Presses Universitaires de France, 2003.

FREEDMAN, L. The Evolution of Nuclear Strategy. Londres: McMillan, 1981.

FRIESER, K-H. The Blitzkrieg Legend - The 1940 Campaign in the West. Annapolis: Naval Institute Press, 2005.

GARTHOFF, R. L. La doctrine militaire soviétique. Paris: Plon, 1952.

GAT, A. A History of Military Thought from Enlightenment to the Cold War. Oxford: Oxford University Press, 2001.

GENETTE, G. Seuils. Paris: Seuil, 1987.

GOLTZ, C. von der. Rosbach et Iéna - Recherches sur l'état physique et intellectuel de l'armée prussienne pendant l'époque de transition du XVIIIe au XIXe siècle. Paris: Hinrichsen, 1890.

GONZALES DE LEON, F. "Doctors of the Military Discipline": Technical Expertise and the Paradigm of the Spanish Soldier in the Early Modern Period. Sixteenth Century Journal, v. 27, n. 1, p. 61-85, 1996.

GRIFFITH, P. Military Thought in the French Army 1815-1851. Manchester: Manchester University Press, 1989.

Battle Tactics of the Western Front - The British Army's Art of Attack 1916-18. New Haven: Yale University Press, 1994.

GUDMUNDSSON, B. I. Stormtroop Tactics - Innovation in the German Army, 1914-1918. Westport: Praeger, 1995. 
Validar a Guerra: A Construção do Regime de Expertise Estratégica

HABECK, M. Storm of Steel - The Development of Armor Doctrine in Germany and the Soviet Union, 1919-1939. Ithaca: Cornell University Press, 2003.

HACKING, I. Entre science et réalité - la construction sociale de quoi? Paris: La Découverte, 2001.

HALE, J. R. War and Society in Renaissance Europe, 1450-1620. Baltimore: The Johns Hopkins University Press, 1985.

HAMLEY, E. B. The Operations of War Explained and Illustrated. Londres: William Blackwood and Sons, 1878.

HANSON, V. D. Le modèle occidental de la guerre - la bataille d'infanterie dans la Grèce classique. Paris: Les Belles Lettres, 1990.

HARARI, Y. N. Renaissance Military Memoirs - War, History and Identity, 1450-1600. Woodbridge: Boydell Press, 2004.

HERKEN, G. Counsels of War. Nova Iorque: Oxford University Press, 1987.

HERSH, S. Dommages collatéraux. Paris: Gallimard, 2006.

HEUSER, B. NATO, Britain, France and the FRG: Nuclear Strategies and Forces in Europe 1949-2000. Londres: MacMillan, 1997.

HIGHAM, R. The Military Intellectuals in Britain 1918-1939. New Brunswick: Rutgers University Press, 1966.

HOWARD, M. (Org.). The Theory and Practice of War. Londres: Cassel, 1965.

JERVIS, R. War and Misperception. Journal of Interdisciplinary History, v. 18, n. 4, p. 675-700, 1988.

JOHNSON, D. E. Fast Tanks and Heavy Bombers - Innovation in the US Army, 1917-1945. Ithaca: Cornell University Press, 2003.

JOHNSTON, A. I. Cultural Realism - Strategic Culture and Grand Strategy in Chinese History. Princeton: Princeton University Press, 1995.

JONES, R. W. Security, Strategy, and Critical Theory. Boulder: Lynne Rienner, 1999.

JOXE, A. Voyage aux sources de la guerre. Paris: Presses Universitaires de France, 1991. 


\section{Christophe Wasinski}

KAPLAN, F. The Wizards of Armageddon. Nova Iorque: Touchstone, 1983.

KEEGAN, J. A History of Warfare. Londres: Pimlico, 1993.

KENNEDY, P. M. War Plans of the Great Powers, 1880-1914. Londres: Allen \& Unwin, 1979.

KLEINSCHMIDT, H. Using the Gun: Manual Drill and the Proliferation of Portable Firearms. The Journal of Military History, v. 63, n. 3, p. 601-629, jul. 1999.

KRAUSE, K.; WILLIAMS, M. C. From Strategy to Security: Foundations of Critical Security Studies. In: Critical Security Studies - Concepts and Cases. Londres: University College London Press, 1997.

KRISTEVA, J. Semeiotike - recherche pour une sémanalyse. Paris: Seuil, 1969.

LANGENDORF, J-J. Faire la guerre: Antoine-Henri Jomini. 2 vol. Genebra: Georg, 2004.

LARSON, R. H. The British Army and the Theory of Armored Warfare 1918-1940. Newark: University of Delaware Press, 1984.

LATOUR, B. Nous n'avons jamais été modernes - essai d'anthropologie symétrique. Paris: La Découverte, 1991.

La science en action - introduction à la sociologie des sciences. Paris: La Découverte, 2005.

Portrait de Gaston Lagaffe en philosophe technique. In: Petites leçons de sociologie des sciences. Paris: La Découverte, 2006.

Sur le culte moderne des dieux faitiches. Paris: Les Empêcheurs de Penser en Rond/La Découverte, 2009.

LINDEMANN T. Penser la guerre - l'apport des constructivistes. Paris: L'Harmattan, 2008.

LUVAAS, J. The Military Legacy of the Civil War - The European Inheritance. Chicago: University of Chicago Press, 1959.

The Education of an Army - British Military Thought 1815-1940. Chicago: University of Chicago Press, 1964. 
Validar a Guerra: A Construção do Regime de Expertise Estratégica

(Org.). Frederick the Great on the Art of War. Nova Iorque: Free Press, 1966.

LYOTARD, J-F. La condition postmoderne. Paris: Minuit, 1979.

MACLUHAN, M. La Galaxie Gutenberg face à l'ère électronique - les civilisations de l'âge oral à l'imprimerie. Paris: Marne, 1967.

MAQUIAVEL, N. A arte da guerra. Brasília: Editora Universidade de Brasília, 1982.

MAUSS-COPEAUX, C. Appelés en Algérie - la parole confisquée. Paris: Hachette, 1998.

MEARSHEIMER, J. J. Liddell Hart and the Weight of History. Nova Iorque: Brassey's, 1988.

NENNINGER, T. K. The Leavenworth Schools and the Old Army, Education, Professionalism, and the Officer Corps of the United States Army, 1881-1918. Londres: Greenwood, 1978.

ODOM, W. O. After the Trenches-The Transformation of U.S. Army Doctrine, 1918-1939. College Station: Texas A\&M University Press, 1999.

PANOFSKY, E. La perspective comme forme symbolique. Paris: Minuit, 1975.

PARET, P. Clausewitz and the State. Nova Iorque: Oxford University Press, 1976.

(Org.). Makers of Modern Strategy from Machiavelli to the Nuclear Age. Oxford: Clarendon Press, 1986.

POIRIER, L. Les voix de la stratégie, généalogie de la stratégie militaire Guibert, Jomini. Paris: Fayard, 1985.

POLLAK, M. D. Military Architecture Cartography \& the Representation of the Early Modern European City - A Checklist of Treatises on Fortification in the Newberry Library. Chicago: The Newberry Library, 1991.

QUELOZ, D. De la manoeuvre napoléonienne à l'offensive à outrance - la tactique générale de l'armée française 1871-1914. Paris: Economica, 2009. 


\section{Christophe Wasinski}

REARDON, C. Soldiers and Scholars - The U.S. Army and the Uses of Military History, 1865-1920. Lawrence: University Press of Kansas, 1990.

REMARQUE, E. M. A l’Ouest rien de nouveau. Paris: Livre de Poche, 1988.

RICOEUR, P. Temps et récit. 3 tomos. Paris: Seuil, 1983-1985.

La mémoire, l'histoire, l'oubli. Paris: Seuil, 2000.

ROSS, S. T. From Flintlock to Rifle - Infantry Tactics, 1740-1866. Londres: Cass, 1979.

ROTHENBERG, G. E. The Art of Warfare in the Age of Napoleon. Bloomington: Indiana University Press, 1981.

SCHAFFER, S.; SHAPIN, S. Léviathan et la pompe à air - Hobbes et Boyle entre science et politique. Paris: La Découverte, 1993.

SHAPIRO M. J. Violent Cartographies - Mapping the Cultures of War. Londres: University of Minnesota Press, 1997.

STEINER, B. H. Bernard Brodie and the Foundations of American Nuclear Strategy. Lawrence: University Press of Kansas, 1991.

SUGANAMI, H. Bringing Order to the Cause of Wars Debates. Millennium: Journal of International Studies, v. 19, n. 1, p. 19-36, 1990.

THIÉBLEMONT, A. Expériences opérationnelles dans l'armée de terre: unités de combat en Bosnie (1992-1995). 3 tomos. Les documents du C2SD, n. 42, nov. 2001.

TILLY, C. (Org.). The Formation of National State in Europe. Princeton: Princeton University Press, 1975.

TRAVERS, T. Technology, Tactics, and Morale: Jean de Bloch, the Boer War, and British Military Theory. The Journal of Modern History, v. 51, p. 264-286, jun. 1979.

TUNSTAlL, G. A. Planning for War against Russia and Serbia - Austro-Hungarian and German Military Strategies, 1871-1914. Boulder: Columbia University Press, 1993. 
Validar a Guerra: A Construção do Regime de Expertise Estratégica

WASINSKI, C. Théories des relations internationales, doctrines militaires et pensée stratégique et de sécurité. Les Champs de Mars, n. 14, p. 145-172, 2º sem. 2003.

Produire de la capacité de gestion de crise internationale : le cas de l'OTAN pendant les années 2000. Cultures \& Conflits, n. 75, p. 15-31, inverno 2009.

WHITE HOUSE. President Bush Outlines Iraqi Threat. 7 out. 2002. Disponível em: <www.gwu.edu/ nsarchiv/NSAEBB/NSAEBB80/new/doc\%2012/President\%20Bush\%20Outlines\%20Iraqi\%20Threat.htm>. Acesso em: 15 dez. 2012 .

WINTON, H. R.; METS, D. R. (Org.). The Challenge of Change - Military Institutions and New Realities, 1918-1941. Lincoln: University of Nebraska Press, 2000.

WOODWARD, B. Plan d'attaque. Paris: Denoël, 2004.

ZUBER, T. Inventing the Schlieffen Plan - German War Planning 1871-1914.

Oxford: Oxford University Press, 2002.

\section{Resumo}

\section{Validar a Guerra: A Construção do Regime de Expertise Estratégica}

O presente artigo interroga os mecanismos do pensamento estratégico que contribuíram para tornar a guerra moderna uma prática social julgada tecnicamente viável e, assim, legítima para os militares. Para tal, a análise proposta inscreve-se nos campos da sociologia pragmática (inspirando-se em autores como Luc Boltanski, Nicolas Dodier e Francis Chateauraynaud) e da sociologia da ciência (apoiando-se fundamentalmente nos trabalhos de Bruno Latour). Por um lado, a sociologia da ciência desenvolveu uma problemática muito fértil acerca da construção dos fatos científicos que servirá de inspiração para este estudo. Por outro lado, a sociologia pragmática elaborou um quadro analítico das ações coletivas que se articula à pesquisa sobre a construção social dos fatos. A partir dessas abordagens, propõe-se investigar a formação de um regime de expertise estratégica que sustenta a legitimidade técnica do uso da força militar. Juntas, a sociologia da ciência e a 


\section{Christophe Wasinski}

sociologia pragmática lançam luz sobre elementos particularmente importantes acerca da questão da guerra.

Palavras-chave: Guerra - Justificação Técnica - Pensamento Estratégico - Sociologia da Ciência - Sociologia Pragmática

\section{Abstract}

\section{Validating War: The Construction of the Strategic Expertise Regime}

This article is intended to contribute to the interpretative analysis of war. For that purpose, it investigates how some apparatuses located in strategic thinking help to make modern war a social practice considered both technically feasible and, at the same time, legitimate for soldiers. In so doing, it makes use of two different but closely related theoretical fields, pragmatic sociology (finding inspiration in the work of scholars such as Luc Boltanski, Nicolas Dodier and Francis Chateauraynaud), and the sociology of scientific knowledge (based mostly on the work of Bruno Latour). On the one hand, the sociology of scientific knowledge has developed a productive questioning of the construction of scientific facts that is particularly relevant to the present research. On the other hand, pragmatic sociology generates a compatible framework able to describe collective actions. The combination of both approaches allows the description of the formation of a strategic expertise regime that supports the technical legitimacy of the use of military force. Together, the sociology of scientific knowledge and pragmatic sociology bring a particularly relevant perspective to research pertaining to war.

Keywords: War - Technical Justification - Strategic Thinking - Sociology of Scientific Knowledge - Pragmatic Sociology 